\title{
Arte postal: práticas pedagógicas no ambiente virtual
}

\author{
Edna Márcia Duarte Toffoli \\ Secretaria do Estado de Educação, Uberlândia, Brasil \\ João Henrique Lodi Agreli \\ Instituto de Artes da Universidade Federal de Uberlândia - UFU, Brasil \\ Elsieni Coelho da Silva \\ Instituto de Artes da Universidade Federal de Uberlândia - UFU, Brasil
}

\begin{abstract}
RESUMO
Este artigo, desdobramento de uma pesquisa do Mestrado profissional em Artes da Universidade Federal de Uberlândia, apresenta a arte postal como possibilidade de práticas pedagógicas no ambiente virtual. Objetiva refletir sobre as potencialidades da arte postal, em um ensino de arte experienciado em rede, com alunos do primeiro ano do ensino médio de uma escola pública em Minas Gerais. A arte postal caracteriza-se por produzir, enviar, receber e reenviar uma produção artística por meio de correios e redes de contatos sociais via internet. Essa experiência coloca os participantes em um sistema dinâmico e de alternância, como espectadores, propositores, produtores e receptores. A experiência pedagógica vivenciada a partir da estrutura de funcionamento e história da arte postal com a participação de professores, artistas e alunos, apresentou-se como meio enriquecedor na mediação e compreensão de conhecimentos em arte. Apontou ainda para a importância de metodologias compartilhadas em produções visuais, como prática motivacional no ensino em artes.
\end{abstract}

PALAVRAS-CHAVE: Ensino de arte. Práticas pedagógicas. Arte postal.

\section{POSTAL ART: PEDAGOGICAL PRACTICES IN THE VIRTUAL ENVIRONMENT}

\begin{abstract}
This article - an unfolding of a research of the Professional Master in Arts of the Federal University of Uberlândia - presents postal art as a possibility of pedagogical practices in the virtual environment. It aims to reflect on the potentialities of postal art, in an art teaching experienced in network, with first year high school students from a public school in Minas Gerais. The postal art is characterized by producing, sending, receiving, and resubmitting an artistic production through post offices and networks of social contacts via internet. This experience places participants in a dynamic and alternating system, such as spectators, proponents, producers, and receivers. The pedagogical experience experienced from the structure of operation and history of postal art with the participation of teachers, artists, and students, presented itself as an enriching medium in the mediation and understanding of knowledge in art. It also pointed out the importance of shared methodologies in visual productions as motivational practice in arts education.
\end{abstract}


KEY WORDS: Art teaching. Pedagogical practices. Postal art.

\section{ARTE POSTAL: PRÁCTICAS PEDAGÓGICAS EN EL ENTORNO VIRTUAL}

\section{RESUMEN}

Este artículo - un desdoblamiento de una investigación de la Maestría Profesional en Artes de la Universidad Federal de Uberlândia - presenta el arte postal como una posibilidad de prácticas pedagógicas en el entorno virtual. Su objetivo es reflexionar sobre las potencialidades del arte postal, en una enseñanza artística experimentada en red, con estudiantes de primer año de secundaria de una escuela pública en Minas Gerais. El arte postal se caracteriza por producir, enviar, recibir y volver a presentar una producción artística por medio de los correos y redes de contactos sociales vía internet. Esta experiencia pone a los participantes en un sistema dinámico y alternativo, como espectadores, proponentes, productores y receptores. La experiencia pedagógica vivida desde la estructura de funcionamiento e historia del arte postal con la participación de profesores, artistas y estudiantes se presentó como un medio enriquecedor en la mediación y comprensión del conocimiento en arte. También señaló la importancia de las metodologías compartidas en las producciones visuales como práctica motivacional en la educación artística.

PALABRAS CLAVE: Enseñanza de arte. Prácticas pedagógicas. Arte postal.

\section{INTRODUÇÃO}

Devido à pandemia causada pelo vírus COVID-19, que atinge amplamente todos os aspectos da sociedade e, diretamente, a educação, com impactos ainda incalculáveis em nível de formação e desenvolvimentos intelectuais entre outros, impõe-se a necessidade de adaptações, a curto prazo, de projetos e práticas pedagógicas que se apresentem eficazes e envolventes ao mesmo tempo. $\mathrm{O}$ ensino foi adaptado para o ambiente virtual de forma abrupta diante das circunstâncias, e o espaço educacional se viu em situação urgente de adaptações e transformações em seu modo de ensinar e aprender o ensino remoto.

Diante desses tempos, os professores estão vivendo a necessidade de práticas pedagógicas dinâmicas e estratégias funcionais, no sentido de alcançar o aluno em sua realidade social e de modo que sejam efetivas no ensino aprendizagem. Essa realidade social diz respeito ao acesso ao mundo virtual, espaço onde o ensino remoto acontece. De acordo com Moran (2020, s/p.), "hoje podemos redesenhar as melhores combinações possíveis na integração de espaços, tempos, metodologias, para oferecer as melhores experiências de aprendizagem à cada estudante de acordo com suas necessidades e possibilidades". Logo, a pandemia, ao acelerar a inclusão digital, de forma mais efetiva no campo educacional, evidenciou a potencialidade da tecnologia virtual para uma mediação flexível, com diversas possibilidades de combinações, arranjos, itinerários e atividades (BACICH; MORAN, 2018) no ensino. 
Buscar metodologias de ensino que deem autonomia e exercício de criticidade ao aluno em sua participação se torna cada vez mais premente. Contudo, foi o que se buscou na prática pedagógica com a arte postal, experienciada com a participação interativa entre professores, alunos e artistas, no primeiro ano do ensino médio, como um possível percurso a ser vivenciado no ambiente virtual e físico, no ensino da arte.

\section{REFERÊNCIAS NO ENSINO EM ARTE: EISNER E BARBOSA}

Contribuíram na definição de metodologias para o ensino de arte postal, neste estudo, concepções de ensino de arte e diretrizes encaminhadas por Eliot Eisner e Ana Mae Barbosa. Eisner, com a "Dicipline Base Art Education - DBAE" (1997), concebeu um ensino de arte dividido em quatro disciplinas: produção de arte, crítica de arte, estética e história da arte. E Barbosa (2011), ao defender a arte como uma área de conhecimento, desenvolveu a proposta triangular, tendo Eisner como uma de suas referências, em que se articula no ensino de arte, o fazer, a leitura e a contextualização.

Eliot Eisner, professor de Arte e Educação na Universidade de Standford, Califórnia, e pesquisador sobre os planejamentos para as práticas de ensino, assim como de outros aspectos do ambiente escolar, juntamente com outros pesquisadores, sistematizaram o programa de disciplinas para o ensino da arte na década de 1980: o Dicipline Base Art Education (DBAE). Sob sua ótica, a produção em arte permite ao aluno criar imagens de modo inteligível, experimentando materiais e técnicas. A crítica, por sua vez, potencializa a capacidade do aluno de ver e compreender uma imagem além da arte hegemônica e do que ela representa no mundo. A história da arte ensina o contexto da arte no tempo e no lugar, já que "nenhuma forma de arte existe em um vácuo descontextualizado" (EISNER, 1997, p. 83). A estética, a última disciplina a se juntar ao ensino da arte, complementa as bases teóricas com a avaliação sobre a qualidade da arte em questão.

No Brasil, também na década de 1980, a arte-educadora Ana Mae Barbosa sistematizou a elaboração de uma construção de conhecimentos em artes, a Proposta Triangular, que "caracterizou-se pela entrada da imagem, sua decodificação e interpretações na sala de aula junto com a já conquistada expressividade" (BARBOSA; COUTINHO, 2011, p. 31). Uma proposta de ensino de arte que articula ações de ler, fazer e contextualizar, cada uma com desafios específicos para a formação e a prática docente.

A leitura de imagem demanda conhecimento e estratégias metodológicas distintas, a depender dos objetivos de ensino trabalhados pelo professor. Como enfatiza Rizzi (2003, p. 66), "a construção do conhecimento em Arte acontece quando há a interseção da 
experimentação com a codificação e com a informação". O fazer demanda compreensão e experiências do processo de criação pelo professor para conceber, didaticamente, meios para que seus alunos possam, em suas produções visuais, exercitar a autonomia, a leitura crítica e os aspectos estéticos. E a contextualização, mais que da obra ou da imagem utilizada para leitura, envolve outras dimensões, as quais se vinculam a uma decodificação de si, do outro e do mundo, e suscita uma complexa abordagem e um olhar para as questões contemporâneas, em que o aluno é pensado como um sujeito leitor inserido no mundo.

Tanto o DBAE como a Proposta Triangular corroboram para as transformações no ensino da arte até os dias de hoje, uma vez que se espalharam pelo mundo e foram referência para muitos professores de arte. São propostas que enfatizam campos de conhecimentos fundamentais no ensino de arte, mas que, como adverte Barbosa (2014, p. 26-27), a "metodologia é construção de cada professor em sala de aula", o que significa que a articulação entre os vértices de conhecimentos que estruturam a abordagem triangular podem ter uma alternância, serem explorados em zigue-zague, de acordo com a proposta de cada professor, em seu modo de ensinar.

Desenvolver metodologia de ensino em arte tem se constituído um desafio constante para professores, uma vez que o conhecimento e a vivência das práticas propostas em sala de aula devem ser experenciadas pelo professor. Tais desafios que vão do acesso - falta de estrutura de computadores e rede de internet funcionando -, até a disposição do aluno em participar e colaborar para seu próprio aprendizado, envolvendo questões sociais, políticas e culturais. Posto isso, é perceptível a necessidade de experiências práticas em arte que envolvam o aluno em reflexões para a construção do saber nesse tempo presente, tão tecnológico e transitório; metodologias que sugiram uma movimentação na integralização do que interessa ao aluno e que façam mover sua participação e curiosidade.

A importância e a necessidade da imagem no ensino de arte justificam-se por provocar a imaginação dos alunos, em uma conexão que os desperta para a leitura de mundo por meio da imagem e de sua contextualização. De acordo com Rizzi (2003, p. 67), na leitura de uma obra de arte, "o objeto de interpretação é a obra e não o artista, não justificando processos adivinhatórios na tentativa de descobrir as "intenções do artista"'. Tal assertiva leva a perceber que o sujeito leitor, a obra e o contexto, dentro de uma interpretação, são peças-chaves para considerar a coerência, a abrangência e a possibilidade, entre outros, sem o reducionismo da obra pelo certo ou errado, isto é, o aluno faz sua própria interpretação, de acordo com seus entendimentos e referenciais. 
A arte é um modo de expressão importante para os adolescentes, diante da fase de transição geradora de alterações físicas, emocionais e sociais. Regina Machado comenta (1988 apud BARBOSA, 2014, p. 31):

[...] que a arte tem, de fato, uma função específica nesta fase da vida do indivíduo, em que ele deixou de ser criança, em que se vê como consciência interrogante e ainda não é adulto. Comecei falando da imaginação porque ela é indissociável da atividade artística, uma não existe sem a outra. A princípio considerei a imaginação como potencialidade humana fundamental para qualquer idade ou atividade; não existe pensamento genuíno sem imaginação.

A imaginação está na base do aprendizado, a partir dela, o aluno se arrisca a perguntar, a perceber como algo lhe parece coerente, possível. No ensino e na aprendizagem existe a necessidade de disparadores que impulsionem a curiosidade e a participação. Ostrower (2014, p. 31) diz que "o que dá amplitude à imaginação é essa nossa capacidade de perfazer uma série de atuações, associar objetos, eventos, poder manipulá-los, tudo mentalmente [...]”. Essa capacidade imaginativa dinâmica pode gerar inúmeros questionamentos que, na arte, não se precisa respondê-los, e sim vivê-los, experimentá-los.

\section{A ARTE POSTAL: TRILHAS, HISTÓRIAS, REFLEXÕES E POSSIBILIDADES}

Ao escolher a arte postal como conteúdo a ser explorado no ensino de arte, alguns questionamentos podem nortear a prática docente junto aos alunos. $\mathrm{O}$ que é arte postal? De onde veio? Como funciona? O que se pode aprender a partir dela? A arte postal, segundo Brusky (2006, p. 374), também chamada de "Arte Correio, Mail Art, Arte por Correspondência, Arte a Domicílio", surge na história da arte como meio de comunicação, linguagem e hibridismos no que se refere à criação, materiais e técnicas. Um fluxo de imagens que transita pelo correio, sofrendo intervenções temporais e físicas, cruzando lugares, desenvolvendo contatos através de trabalhos de arte em pequeno formato, concebida por artistas e não artistas, nacionais e internacionais.

Criada por Ray Johnson, na década de 1960, e impulsionada pelos integrantes do grupo Fluxos, a arte postal tem como objetivo a troca de ideias, poesias e experimentos artísticos entre seus participantes, estabelecendo uma rede de contatos - artistas/participantes que trocam tais experimentos artísticos (HOME, 2004) - que crescia exponencialmente em vários países, daí o uso do correio para concretizar esse intercâmbio. A arte postal, segundo Home (2004, p. 109), “desenvolveu-se a partir de um clima libertador criado pelo assalto dos trabalhadores Fluxus à 
cultura dominante", seus participantes apresentavam ideias políticas, sociais, culturais e até mesmo campanhas para presos políticos e exaltação de personalidades de suas culturas.

A origem dessa arte encontra-se nas vanguardas. No movimento Dadá, pelo suporte subversivo, na defesa da arte fora das instituições destinadas a ela, dos museus e das galerias e na técnica da colagem. Com Marcel Duchamp e a nova concepção dada à arte, considera-se que a ideia é mais importante que o produto final, a obra. Segundo Smith (2000, p. 182), "Duchamp deu a entender que a arte podia existir fora dos veículos convencionais e "manuais" da pintura e da escultura[...]", assim, a ligação da arte postal com os movimentos de vanguarda vem do início da dessacralização do objeto na arte e da valorização da ideia. O artista usou em suas obras a linguagem verbal e visual, materiais alternativos e diversificados, e foi referência para os movimentos e tendências artísticas que se seguiram.

$\mathrm{Na}$ arte conceitual, em meados da década de 1960, artistas influenciados por Duchamp, com suas novas concepções, ideologias e modos de ver e viver a arte, multiplicam a ideia de interesse no contexto da obra e a rejeição ao objeto na arte. Como afirma Smith (2000, p. 183), "a arte como ideia foi decomposta e desdobrada em arte como filosofia, como informação, como linguística, como matemática, como autobiografia, como crítica social, como risco de vida, como piada e como forma de contar histórias", sendo a arte postal um desses desdobramentos da conceitual. Nesse sentido, a conexão entre meios de comunicação e imagens para reproduzir ideias constitui-se em uma linguagem artística.

Mais especificamente, como cerne da origem da arte postal, tem o grupo Fluxus, liderado por George Maciunas ${ }^{1}$, composto por um grupo de artistas, músicos e performers que buscaram expandir seus trabalhos e apresentações ao convocarem a participação do espectador como parte da ação, a partir de publicações com informativos de suas atividades. O grupo manteve um viés temático político e cultural com protestos, piquetes e ataques à "cultura séria" por um tempo, até a tendência estética diminuir a propensão política. Na sequência, diminuíram os eventos ao vivo e passaram a publicações mais frequentes e trocas de experimentos e ideias através do correio. Um artista próximo ao grupo, Ray Johnson, participou dessa troca e levou adiante a chamada mail art ou arte postal (HOME, 2004).

O trabalho de Johnson com a arte postal é constituído de material precário e sem valor artístico de mercado. Segundo Home (2004, p. 109), “consiste basicamente de cartas, muitas vezes acompanhadas de rabiscos, desenhos e mensagens carimbadas. O trabalho é leve e bem humorado; em vez de ser vendido, é geralmente enviado pelo correio para amigos e

\footnotetext{
${ }^{1}$ George Maciunas nasceu em Kaunas, Lituânia, 1931, foi organizador e articulador do grupo Fluxus até sua morte, em 9 de maio de 1978 (HOME, 2004).
} 
conhecidos". A lista de Johnson para envio desses trabalhos é chamada de rede, ou seja, o ponto de contato entre as pessoas, a troca de notícias e ideias a longas distâncias, assim, o movimento se espalhou pela América do Norte, pela Europa e pelo Japão, crescendo de maneira excepcional numa nova modalidade de arte, a arte postal (HOME, 2004).

No Brasil, essa prática teve seu tempo de reconhecimento e aquecimento durante o período da contra cultura, na década de 1960, quando o país vivia um cerceamento em todas as formas de expressão. O pernambucano Paulo Brusky, artista visual multimídia e poeta, teve, nesse período, participação importante na arte postal, tanto em sua divulgação quanto na propagação. Ele diz que, "na Arte Correio, a arte retoma suas principais funções: a informação, o protesto e a denúncia” (BRUSKY, 2006, p. 374).

O uso do correio foi fator determinante, que possibilitou o intercâmbio de participantes de culturas diferentes a longas distâncias. Para Brusky (2006, p. 375), “O correio é usado como veículo, como meio e como fim fazendo parte/sendo a própria obra [...]”, visto que, dessa forma, o percurso da obra caracteriza-se por interferências físicas, por alterações visuais através dos carimbos de registro, e por fatores temporais, como manchas provocadas por umidade. Usavase também esse meio, de acordo com o artista citado, para que se caracterizasse uma arte de estrutura processual, uma vez que a concepção da arte postal se aplica em produzir, enviar, receber e reenviar, o que coloca o espectador em lugar de público, produtor e receptor.

$\mathrm{Na}$ arte postal existe uma cadeia (rede) de circulação que se alterna e reveza entre propositor, produtor, receptor e espectador. O artista postalista atuante reveza de posição nessa cadeia de circulação, de acordo com a frequência de participação. Sendo assim, existem algumas situações possíveis e a definição pode ser resumida da seguinte forma:

- O propositor é aquele que propõe, que lança uma convocatória;

- O produtor é aquele que produz, cria para envio, para participação;

- O receptor é aquele que recebe algum trabalho e repassa, via correio ou e-mail;

- $\quad$ O espectador é aquele que aprecia a arte postal em uma exposição ou coleção.

A arte postal, em sua dinâmica, antecipou as redes sociais, quando não existia internet rápida e fácil como hoje. Nessa conexão entre pessoas, encontra-se a arte postal integrada a essa rede virtual que facilita e apresenta-se como nova ferramenta, um meio para a relação entre os artistas postalistas. No contexto de um mundo virtual, favorece uma conexão direta com alunos de todas as idades, uma vez que as redes de contato dessa arte estão inseridas na grande rede, a internet. Inicialmente, as convocatórias eram enviadas aos participantes da lista do propositor através do correio, respondidas e repassadas. Essas ações da arte postal foram surgindo à medida que se expandia e cada artista criava um tipo de interação com sua rede de contatos. 
Na década de 1970, foi criado o correio eletrônico ou, e-mail, como se concebe hoje, e essa troca de mensagens eletrônicas permitiu que a distribuição de convocatórias se expandisse com mais rapidez e sem custo, aumentando a interatividade entre participantes. A entrada da arte postal na rede da internet possibilitou as pessoas conhecerem essa arte pelo alcance que a tecnologia permite. Padín (1999, s/p) vê o e-mail "como suporte para a arte postal”, assim como o papel, o fax, a reprografia. Vê-se, então, que a evolução dessa comunicação artística acompanha as inovações e as possibilidades que a tecnologia oferece aos participantes.

Desde então, existem artistas que fazem proposições para o envio de trabalhos por $e$ mail, mas, principalmente nesses tempos pandêmicos, o crescimento das proposições de convocatórias para envios virtuais estão sendo consideráveis. Com a distribuição da convocatória pelas redes sociais (Facebook e Instagram), o propositor, ao receber esses trabalhos via e-mail, pode fazer a impressão, caso vá expor o material; existem também exposições virtuais em blog's e nas próprias redes sociais. $\mathrm{O}$ artista posta todo o material recebido, registrado em fotografias, com as devidas informações. Nesse sentido, a participação dos alunos na arte postal a partir do ambiente virtual pode alcançar interesse e conexão maiores, além do custo zero (visto que no envio pelo correio existem as taxas).

Nas imagens abaixo podem ser vistos exemplos de convocatórias de arte postal e como ela se movimenta e se comporta nas redes sociais. Na Figura 1, uma convocatória recebida por e-mail, que informa suas bases: o meio de envio, o objetivo, o destino e a apresentação do material recebido. O propositor decide as bases de sua convocatória conforme seu objetivo.

Figura 1: Convocatória recebida por e-mail, 2020.

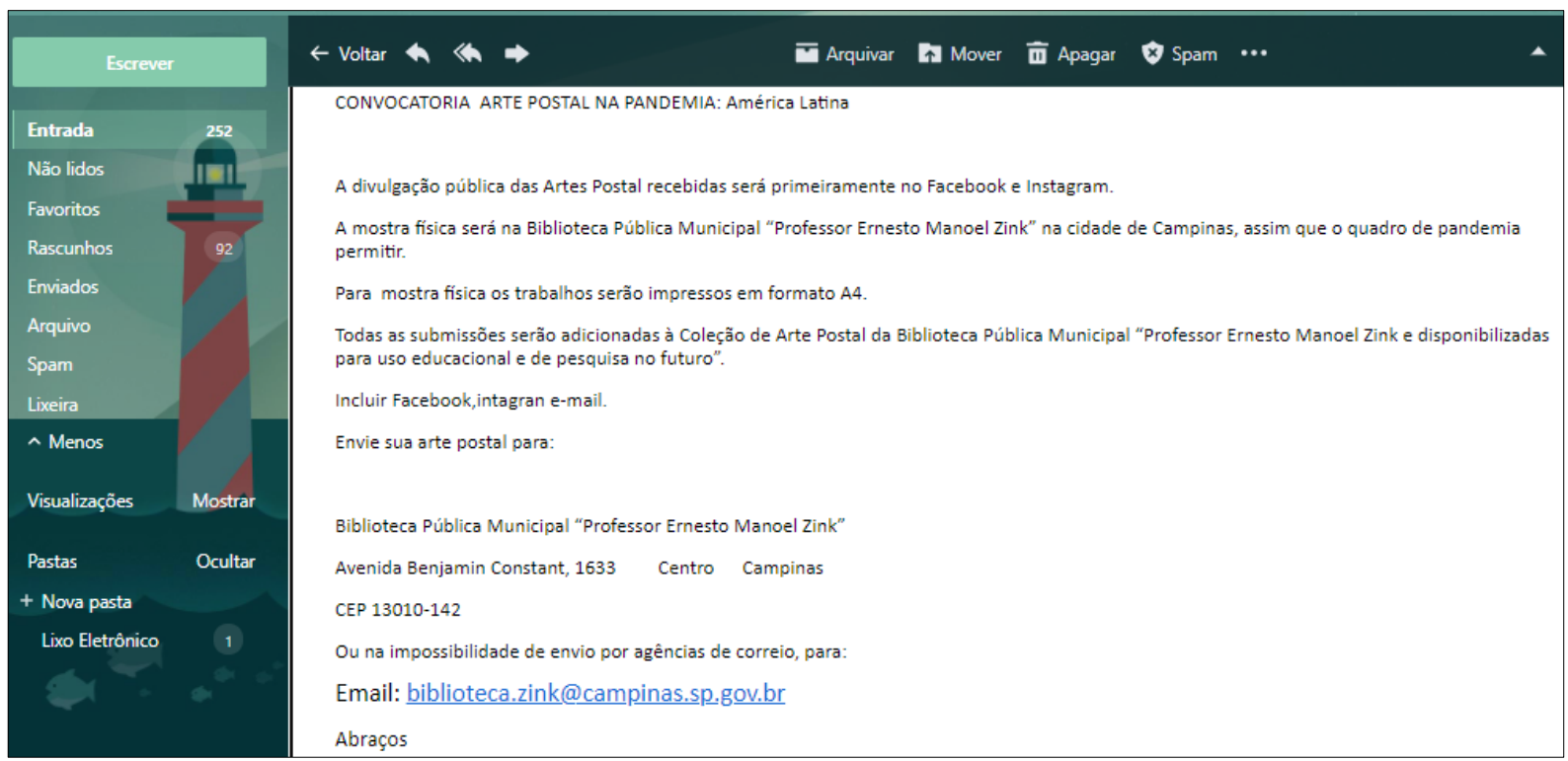

Fonte: Autores, print de tela, página e-mail (https://mail.yahoo.com/) 
As convocatórias também são postadas nas redes sociais Facebook e Instagram, com as devidas informações acerca do tema e da proposta, alcançando uma propagação de forma exponencial (que pode ser observado pelo número de compartilhamentos nas redes sociais). E essa questão é positiva, visto que, quanto mais participantes alcançar, mais trabalhos de arte postal para o projeto e mais ideias se somarão à proposta.

Na Figura 2, uma das muitas postagens da "V Big"" (Bienal Internacional de Guarulhos de Pequeno Formato), que se constitui em uma proposta de arte postal que acontece presencialmente, com exposição física e virtual (no Blog do proponente) dos trabalhos recebidos pelo correio. Excepcionalmente no ano de 2020, devido ao período pandêmico, adaptou-se para acontecer integralmente no ambiente virtual. A Big acontece na cidade de Guarulhos-SP, foi criada e organizada pelo grupo de artistas do Coletivo $308^{3}$ e, como toda proposta de arte postal, tem um tema e as bases para participação.

Figura 2: Postagem da Big Bienal no Instagram, trabalho de Jazuli A. Moenib, técnica mista, 2020.

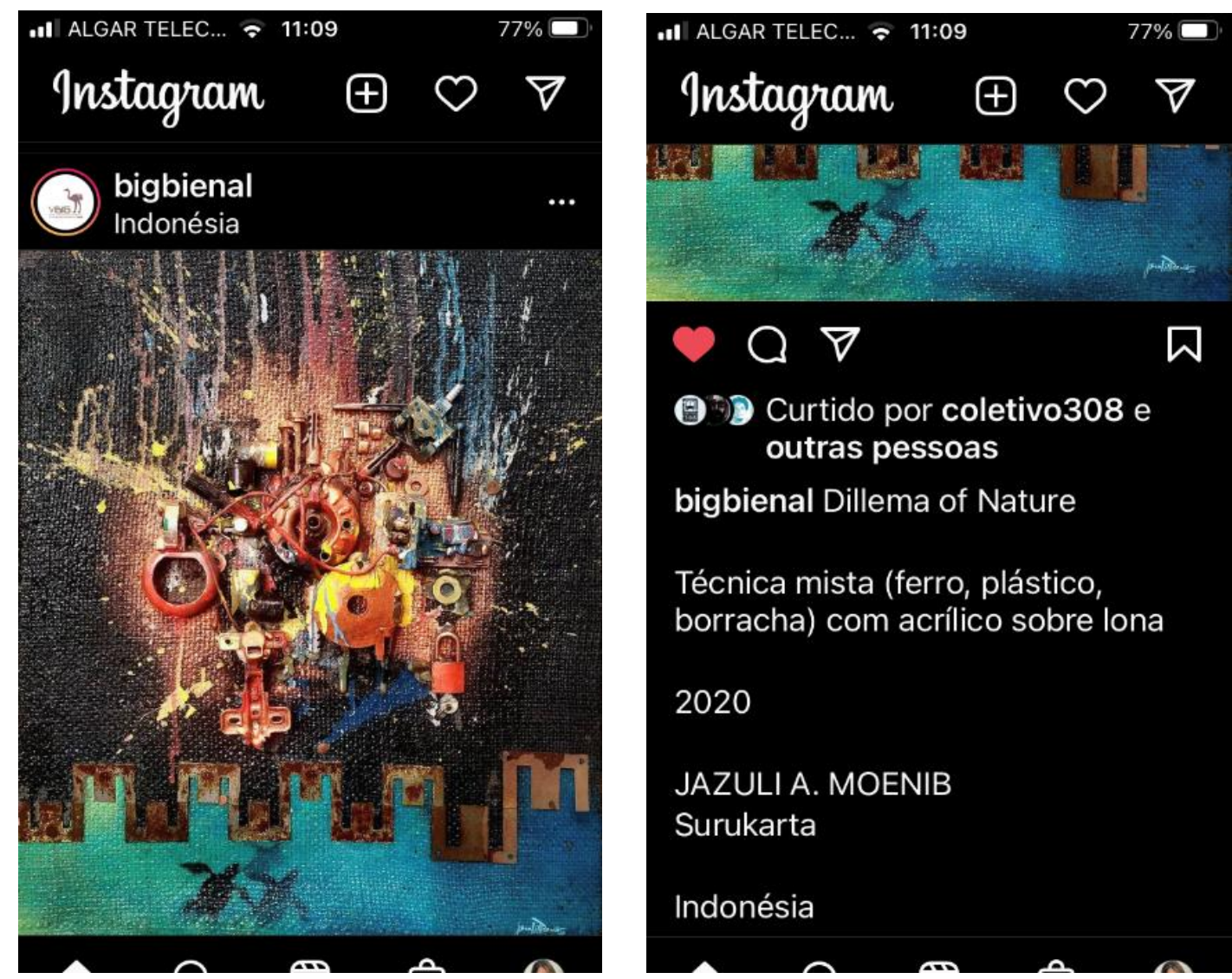

Fonte: Instagram @bigbienal

\footnotetext{
${ }^{2}$ Acesso em: https://5bigpequenoformato.blogspot.com/2020/10/o-que-e-big.html

${ }^{3}$ Coletivo 308 é um grupo de artistas e educadores que produzem obras, oficinas e cursos de arte coletivamente, com sede na cidade de Guarulhos/SP, desde 2006.
} 
Nesse contexto, a arte postal está em plena circulação no ambiente virtual e físico, de acordo com seus propositores e participantes. É importante dizer que a arte postal sempre acompanhou as transformações dos meios de comunicação, principalmente por ser um meio de comunicação artístico, o que mostra as possibilidades que essa modalidade artística traz aos professores de arte em experiências de participação que podem ser levadas para a sala de aula como prática pedagógica variante, de acordo com seus participantes e suas escolhas, seja de temas a serem trabalhados, seja de plataformas utilizadas e processos de criação.

\section{A ARTE POSTAL COMO PRÁTICA PEDAGÓGICA: POSSIBILIDADES}

Arte e vida são vistas como uma aproximação feita pela mediação do professor em sala de aula, a partir do "exercício de reflexão em torno do ensino de artes, que gera espaços para a construção do saber/fazer artístico implicado ao ato de escuta, expressão e problematização das múltiplas vozes que compõem as relações em sala de aula" (RACHEL, 2014, p. 22), relações essas que são importantes na construção do conhecimento, numa educação que oportuniza situações de aprendizado por intermédio das experiências vividas pelos alunos e pelos professores dentro e fora da sala de aula.

Os processos educacionais específicos de cada professor diante de seus alunos, assim como a forma com que organiza os conteúdos em aulas, dependem de fatores como disponibilidade em estrutura física, material e tempo hábil para realização de práticas, que são parte da construção do ensino e da aprendizagem em arte, mas também são parte integrante de sua produção, pois, no momento do planejamento, seja de aulas, seja de projetos ou modos de avaliação, existe a criação por parte do professor.

Propor participação em rede aos alunos com produção, envio e recebimento de arte postal proporciona o entendimento da estrutura de funcionamento da arte postal e viabiliza conhecimentos artísticos. A vivência no processo de participação clarifica o funcionamento dessa arte, suas implicações em trocas, integralização e coletividade na obra. Esse papel híbrido, de professor e de artista, desempenhado em sala de aula, incentiva e estimula ambas as partes no processo de criação. O compartilhamento de imagens com os alunos funciona como referência visual, tanto em técnicas como em material.

A participação na rede de arte postal, Figura 3, apresenta a rede de artistas postalistas e o revezamento em cada situação que se encontra, quando propõe uma convocatória e aguarda receber as participações de outros participantes/artistas e quando produz trabalhos de arte postal para enviar a outros artistas e participantes (respondendo a uma convocatória), assim, 
esse artista postalista está na rede de arte postal: produzindo, enviando e recebendo. Em sala de aula, o professor pode criar, juntamente com os alunos, convocatórias para receber trabalhos de arte postal, assim como propor a produção para envio.

Figura 3: Esquema de participação na arte postal

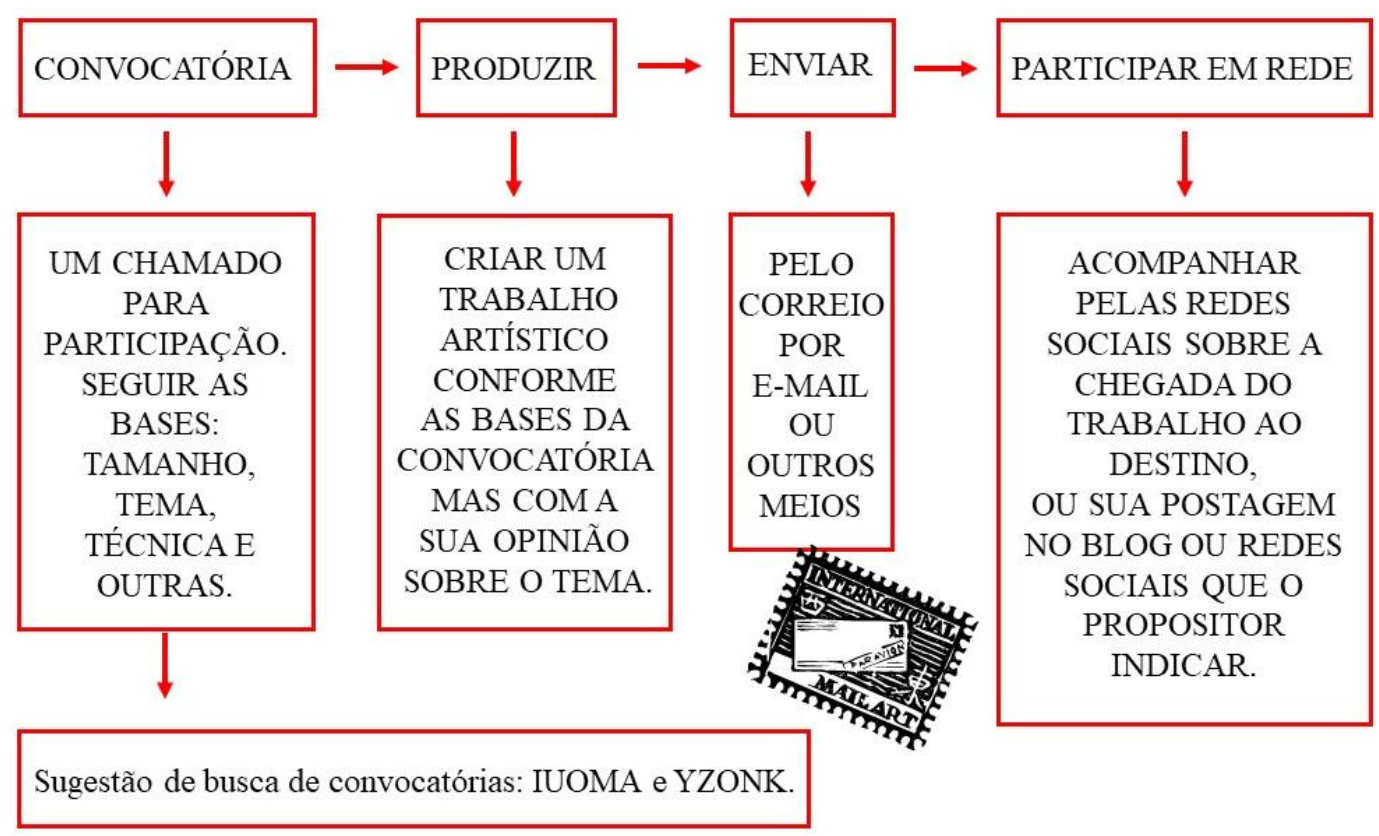

Fonte: Esquema elaborado pelos autores.

No ensino da arte, a provocação criativa no/do aluno parte da referência dada pelo professor, é preciso que as atividades práticas proporcionadas abordem os artistas e as tendências artísticas contextualizadas, para que haja uma disposição na criação por parte do aluno. Para Barbosa (2003, p. 18), “[...] desconstruir para reconstruir, selecionar, reelaborar, partir do conhecido e modificá-lo de acordo com o contexto e a necessidade são processos criadores, desenvolvidos pelo fazer e ver Arte [...]", ou seja, os subsídios são de suma importância no fazer dos alunos.

Ao apresentar aos alunos a história da arte postal e sua estrutura de funcionamento, a partir de suas heranças e referências, foram trabalhados, no ensino, os movimentos artísticos, as técnicas, os artistas e os materiais que compõem toda essa história. Um percurso de aprendizados artísticos permeados de práticas, em participação e produção de arte (Quadro $1)$. 
Quadro1: Conteúdos geradores de práticas a partir da vivência com a arte postal

\begin{tabular}{|c|c|c|}
\hline $\begin{array}{l}\text { MOVIMENTO } \\
\text { ARTÍSTICO }\end{array}$ & ARTISTAS & REFERÊNCIAS \\
\hline Futurismo & $\begin{array}{l}\text { Giacomo Balla } \\
\text { Ivo Pannagi }\end{array}$ & $\begin{array}{l}\text { - Uso do cartão postal, um meio potente e } \\
\text { inovador para criação artística. }\end{array}$ \\
\hline Dadaísmo & $\begin{array}{l}\text { Marcel Duchamp e } \\
\text { Kurt Schwitters }\end{array}$ & $\begin{array}{ll}\text { - } & \text { Experimentações em reproduções e } \\
\text { interferência; } \\
\text { - } \\
\text { Autonomia da arte, subversão e espírito } \\
\text { ideológico; } \\
\text { - Liberdade de participação, técnica colagem } \\
\text { e uso do correio; } \\
\text { - } \quad \text { Uso de materiais precários, reutilizados. }\end{array}$ \\
\hline Surrealismo & Max Ernst & $\begin{array}{l}\text { - } \quad \text { Técnicas Frottage, Drapping e Grattage; } \\
\text { - } \quad \text { Colaboração e coletividade na rede de arte } \\
\text { postal; } \\
\text { - } \quad \text { Sem distinção entre o público e privado; } \\
\text { - } \quad \begin{array}{l}\text { Espaço comum a artistas famosos e } \\
\text { anônimos; } \\
\text { - }\end{array} \\
\text { Jogos coletivos (add/pass, add/return, } \\
\text { cadavre exquis). }\end{array}$ \\
\hline Arte Conceitual & Grupo Fluxus & $\begin{array}{l}\text { - } \quad \text { Hibridismo nas técnicas; } \\
\text { - Uso das novas mídias da época (xerox e e- } \\
\text { mail); } \\
\text { - } \quad \text { Predomínio da ideia sob a estética, } \\
\text { - } \quad \text { Meios de circulação e apresentação da arte. }\end{array}$ \\
\hline
\end{tabular}

Fonte: Elaborado pelos autores.

No Quadro 1, encontram-se movimentos artísticos, artistas e características herdadas pela arte postal que favorecem algumas atividades a serem trabalhadas em sala de aula e adaptadas ao ambiente virtual. Enviar as imagens por e-mail ou até mesmo aplicativos, como o Whatsapp, permite fazer interferências digitais conforme a proposta e as possibilidades do professor e dos alunos. Essas ações caracterizam todo o funcionamento e a participação em rede (internet), de modo remoto, na arte postal.

Na prática docente experienciada, as atividades partiram de algumas proposições entre os artistas postalistas em sua época. Entre elas, o projeto Silhoutte (add and pass, add and return) e Cadavre Exquis. Em 1976, Ray Johnson iniciou o projeto Silhouette, que consistia em desenhos do perfil de rostos de amigos, artistas e pessoas da mídia no círculo artístico, que eram enviados aos destinatários para que fizessem uma interferência e, na sequência, retornavam ou encaminhavam para outro participante pelo correio. Essas atividades eram chamadas de "adiciona e passa ou adiciona e retorna". Segundo Beatty (2019): 
Os assuntos incluíam um quem é quem da cena de artes e letras de Nova York: Chuck Close, Andy Warhol, Paloma Picasso, James Rosenquist, Richard Feigen, Frances Beatty, William S. Burroughs, Nam June Paik, David Hockney, Peter Hujar e Roy Lichtenstein entre outros (BEATTY, 2019, s/p).

Esses desenhos de perfis serviram como base para colagens e outras técnicas. Os destinatários não eram em sua totalidade artistas visuais, eram também músicos, dançarinos e atores, reafirmando assim a participação democrática da arte postal. As ações "add and pass" ou "add and return" consistiam em enviar uma atividade ao destinatário, com instruções como "por favor, adicione o cabelo da Cher" ou "desenhe um coelhinho" (BEATTY, 2019, s/p). Tais atividades desmistificavam a autoria da obra, visto que o resultado tinha a participação de duas ou mais pessoas, com seus nomes, carimbos e endereços, como mostram as Figuras 4 e 5.

Figura 4: Desenho base para o projeto Silhouetes de Ray Johnson

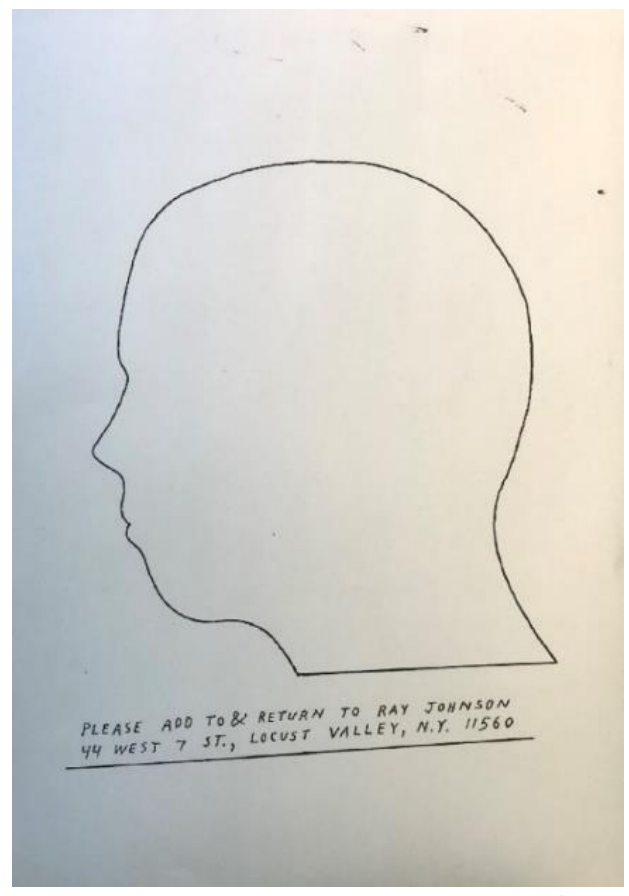

Figura 5: Add and return, de Ray Johnson, com interferências de Hachtman

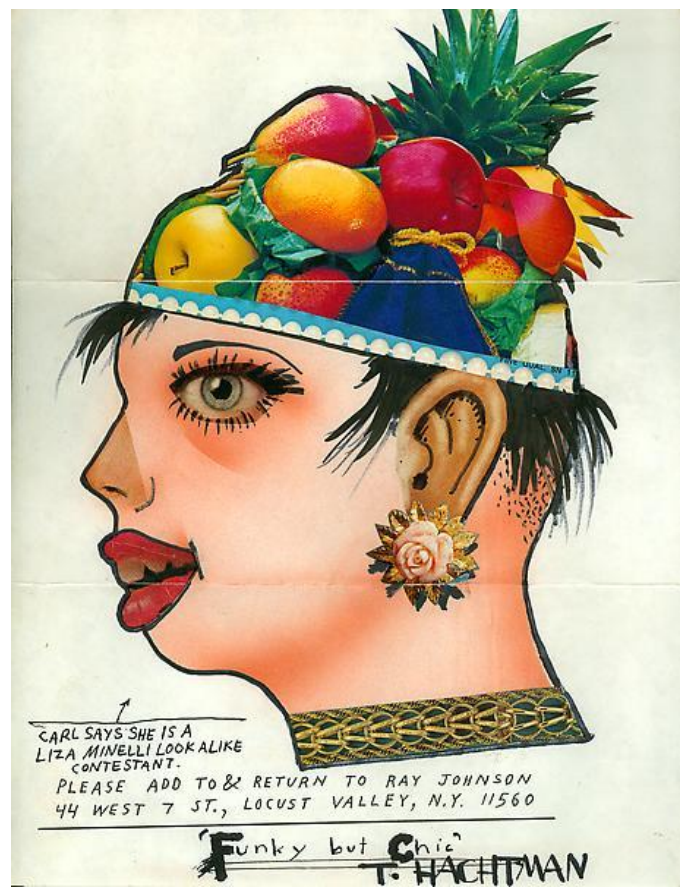

Fonte Figura 4: Compilação da autora ${ }^{4}$

Fonte figura 5: http://www.rayjohnsonestate.com/art/mail-art-and-ephemera/

O jogo “cadavre exquis", traduzindo, cadáver esquisito, surgiu com uma versão escrita, devido ao viés literário do Surrealismo, mas logo apareceu como imagens, como pode ser visto nas Figuras 6 e 7. De acordo com Ades (2000, p. 93):

\footnotetext{
${ }^{4}$ Modificação de imagem coletada do site: http://www.rayjohnsonestate.com/art/from-ray-johnson/works/140/ , acesso em 16/05/2019.
} 
Faziam jogos infantis, como 'cadavre exquis', em que cada jogador desenha uma cabeça, o corpo ou as pernas, dobrando o papel depois de sua vez, de modo que sua contribuição não possa ser vista. As estranhas criaturas que daí resultam forneceram a Miró inspiração para suas telas.

O caráter coletivo, de compartilhamento de autoria e leveza na criação, enfatizava a desmistificação da "aura e a genialidade do artista - onde reside o maior mérito deste jogo e de seus jogadores" (PIANOWSKI, 2013, p. 149), o que permite e incentiva a participação de artistas e não artistas. Além dessas atividades práticas, a produção em arte postal com os alunos também faz parte desse percurso de conhecimentos em arte, visto que a liberdade em técnicas, materiais e temas, como já mencionado, são características presentes na arte postal.

Figura 6: Cadavre exquis, respectivamente, André Breton, Jacqueline Lamba, Yves Tanguy, 1938.

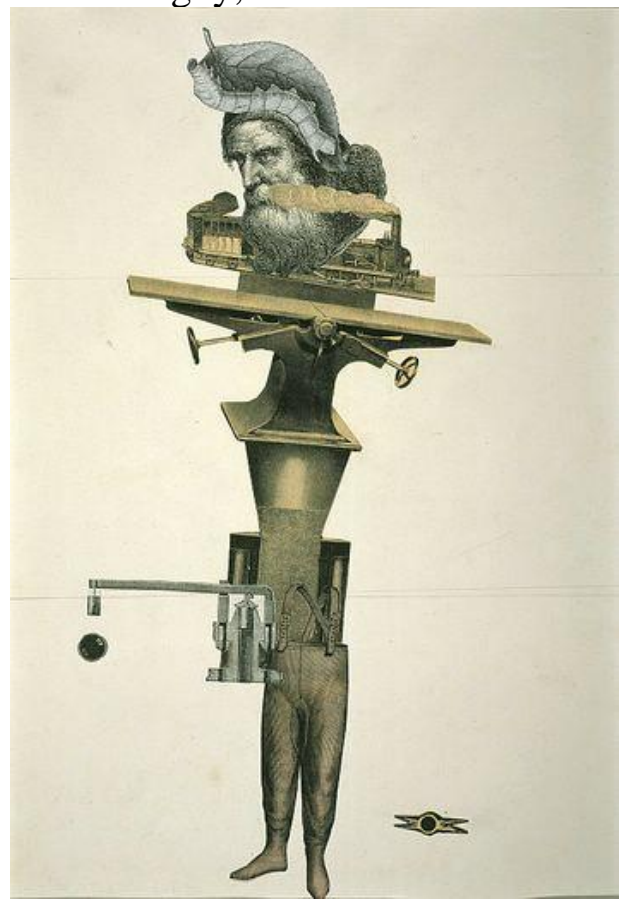

Fonte figuras 6 e 7: www.horizonfrance.com.br/2016/08/cadavre-exquis-0-criacao-coletiva.html

É certo que tantas outras questões não mencionadas no Quadro 1 podem ser abordadas em práticas pedagógicas envolvendo a arte postal, seria pretensão querer explorar em sua totalidade. E isso reforça a propriedade do professor diante da criação de metodologias em planejamentos com práticas pedagógicas criativas, envolvendo conteúdo da disciplina, de acordo com as ferramentas, o tempo e os materiais disponíveis. 


\section{CONCLUSÃO}

Desenvolver metodologias de ensino próprias, criativas e estimulantes sempre foi necessário, mas, no contexto contemporâneo, é inevitável. Os professores, diante de um ensino remoto imposto como necessidade pela pandemia, vivenciada desde 2020 no Brasil, estão tendo que criar metodologias que sejam inovadoras e interativas; adaptar práticas ao conteúdo e demandas curriculares; e romper com resistências frente ao desconhecimento de como utilizar as mídias contemporâneas como uma ferramenta de ensino, de modo a se aproximar do aluno nativo digital em práticas pedagógicas no ambiente virtual. Nesse processo, o professor, ao utilizar o dinamismo das plataformas digitais associadas às redes sociais, cria um vínculo com o mundo digital no qual os alunos estão imersos, o que tem colaborado para pesquisas producentes na construção de conhecimentos. São práticas pedagógicas que potencializam as habilidades dos alunos com a tecnologia e possibilitam desenvolvê-las, uma vez orientadas "pelos princípios de iniciativa, originalidade e cooperação com vistas a liberar suas potencialidades" (BACICH; MORAN, 2018, p. xi).

A arte postal, com suas características e estrutura de funcionamento, entre diversas contribuições para a construção de um conhecimento em arte, e uma alternativa motivacional aos alunos, propicia uma articulação significativa com as demandas de um ensino remoto. Ela não só possibilita uma participação de todo o grupo, professores e alunos, como também viabiliza aprendizados em movimentos artísticos, aos artistas e em suas experiências e movimentações que transformaram a arte ao longo da história. Trilhar esses caminhos das décadas de 1960 e 1970, como o uso das mídias (xerox, e-mail) na arte, o uso dos materiais alternativos e precários, as influências e as referências advindas das vanguardas europeias, são materiais potentes na criação de práticas pedagógicas.

Toda essa contingência de ensino e aprendizado pode conectar professores e alunos em participação no ambiente virtual e físico, reverberando nas possíveis experiências oferecidas pelo percurso criativo em conhecimentos artísticos a partir da arte postal. Perceber essa aproximação de entrelugares, combinado com as ações e as reflexões experimentadas, resulta em aprendizados para todos os envolvidos nesse período pandêmico que estamos vivendo.

\section{REFERÊNCIAS}

ADES, Dawn. Dadá e Surrealismo. In: STANGOS, Nikos. Conceitos da Arte Moderna. Rio de Janeiro: Jorge Zahar Editor, 2000. p. 81-89. 
BACICH, Lilian; MORAN, José Manuel. Metodologias Ativas para uma educação inovadora. São Paulo: Ed. Penso, 2018.

BARBOSA, Ana Mae. A imagem no ensino da arte. São Paulo: Perspectiva, 2014.

BARBOSA, Ana Mae; COUTINHO, Rejane Galvão. Ensino de Arte no Brasil: aspectos históricos e metodológicos. São Paulo: UNESP/REDEFOR, 2011.

BARBOSA, Ana Mae. Inquietações e Mudanças no Ensino da Arte. São Paulo: Cortez, 2003.

BEATTY, Adler. Biografia. Ray Johnson Estate. 2019. Disponível em:

http://www.rayjohnsonestate.com/biography/. Acesso em: 10 fev. 2019.

BRUSKY, Paulo. Arte Correio e a grande rede: hoje, a arte é este comunicado. In:

FERREIRA, Glória; COTRIM, Cecilia (Orgs.). Escritos de artistas: anos 60/70. Rio de Janeiro: Jorge Zahar Editor, 2006, p. 374-379.

EISNER, Elliot. Estrutura e Mágica no Ensino da Arte. In: BARBOSA, Ana Mae (Org.). Arte-Educação: leitura no subsolo. São Paulo: Cortez, 1997, p. 76-92.

HOME, Stewart. Assalto à cultura. São Paulo: Conrad Editora do Brasil, 2004.

MORAN, José Manuel. Como acelerar as mudanças na Educação. Educação Transformadora, 2020. Disponível em: http://www2.eca.usp.br/moran/?p=1678. Acesso em: 25 de nov. de 2020.

OSTROWER, Fayga. Criatividade e Processos de Criação. Petrópolis: Editora Vozes, 2014.

PADÍN, Clemente. El arte correo a finales del siglo. Merz Mail, jun. 1999. Disponível em: http://www.merzmail.net/finales.htm. Acesso em: 15 mar. 2020.

PIANOWSKI, Fabiane. Análisis Histórico del Arte Correo en América Latina. 2013, 332 f. Tesis (Doctorado en Historia del Arte) -Departamento de Historia del Arte, Universidad de Barcelona, 2013.

RIZZI, Maria Christina de Souza. Caminhos Metodológicos. In: BARBOSA, Ana Mae (Org.). Inquietações e mudanças no ensino da arte. São Paulo: Cortez, 2003, p. 63-93.

SMITH, Roberta. Arte conceitual. In: STANGOS, Nikos. Conceitos da Arte Moderna. Rio de Janeiro: Jorge Zahar Editor, 2000, p. 182-192.

\section{SOBRE AS AUTORAS E O AUTOR}

Edna Márcia Duarte Toffoli é Mestre em Artes pelo PROFArtes da Universidade Federal de Uberlândia (UFU), graduada em Educação Artística, habilitação em Artes Plásticas, pela Universidade Federal de Uberlândia (UFU), e tem especialização em Arte e Criatividade pela Universidade de Franca (UNIFRAN) e em Supervisão, Inspeção e Gestão Escolar pela Universidade Cândido Mendes (UCAM). É Professora de Arte na Rede Pública Estadual de Minas Gerais.

E-mail: edna.toffoli@yahoo.com.br

ORCID: http://orcid.org/0000-0001-9091-1307 
João Henrique Lodi Agreli é Doutor em Artes pela Universidade de Brasília (UnB), com pós-doutorado em Artes visuais pela Universidade Federal da Paraíba (UFP). Tem mestrado em Artes pela Universidade de Brasília (UnB) e graduação em Desenho Industrial, Programação Visual, pela Universidade Estadual de Londrina (UEL). É professor do Mestrado Profissional em Artes (PROFArtes) do Instituto de Artes da Universidade Federal de Uberlândia (UFU). Desenvolve pesquisas sobre convergências entre Artes Visuais e Mídias Gráficas.

E-mail: agreli@hotmail.com

ORCID: http://orcid.org/0000-0001-8623-6302

Elsieni Coelho da Silva é Doutora em Educação pela Universidade Federal de Goiás (UFG), Mestre em Educação pela Universidade Estadual de Campinas (Unicamp), graduada em Educação Artística, habilitação em Artes Plásticas, pela Universidade Federal de Uberlândia (UFU). É professora do Mestrado Profissional em Artes (PROFArtes) e do curso de Artes Visuais, da Universidade Federal de Uberlândia (UFU). Desenvolve pesquisas sobre formação do professor, docência universitária, processo de criação e metodologias do ensino em Artes, produção poética em objetos, instalação e pintura. Coordena o grupo "Formação, Prática Educativa e Pesquisa" (ForPEP) e integra a Rede de Pesquisadores sobre professores do Centro-Oeste (REDECENTRO).

E-mail: elsienicoelho@ufu.br

ORCID: https://orcid.org/0000-0002-4483-0765 